\title{
A educação superior no Brasil: os desafios da expansão e do financiamento e comparações com outros países
}

\author{
Vera Lúcia Jacob Chaves \\ Universidade Federal do Pará \\ Nelson Cardoso Amaral \\ Universidade Federal de Goiás
}

\section{Resumo}

artigo discute os desafios existentes na educação superior brasileira para conseguir atingir mais de 30\% de seus jovens com idade entre 18 e 24 anos, matriculados nesse nível educacional. Utilizamos dados financeiros do Instituto Nacional de Estudos e Pesquisas Educacionais Anísio Teixeira - Inep, dentre outras fontes. Os dados apontam que há uma enorme privatização desse nível educacional e uma grande diversificação de instituições e cursos. Os recursos financeiros aplicados na educação pública atingem 5,3\% do Produto Interno Bruto (PIB), o que resulta em um baixo valor por pessoa em idade educacional, quando comparações são realizadas entre o Brasil e diversos países selecionados.

Palavras-chave: Educação superior. Expansão. Financiamento.

\section{Higher education in Brazil: the challenges of expansion and financing and comparisons with other countries}

\begin{abstract}
The article discusses the challenges that exist in Brazilian higher education to achieve more than $30 \%$ of their young people, aged between 18 and 24 years, enrolled in this educational level. We use financial data from the Instituto Nacional de Estudos e Pesquisas Educacionais Anísio Teixeira Inep, among other sources. The data indicates that there is a huge privatization of this educational level and a great diversity of institutions and courses. The financial resources invested in public education reaches 5.3\% of Gross Domestic Product (GDP), which results in a low value per person on education age when comparisons are performed between Brazil and several selected countries.
\end{abstract}

Keywords: Higher education. Expansion. Financing. 
A educação superior no Brasil: os desafios da expansão e do financiamento e comparações com outros países

\section{La educación superior en Brasil: los retos de la ampliación y la finan- ciación y las comparaciones con otros países}

\section{Resumen}

El artículo aborda los desafíos que existen en la educación superior brasileña para alcanzar más del $30 \%$ de sus jóvenes, con edades comprendidas entre 18 y 24 años, matriculados en el nivel educativo. Utilizamos los datos financieros del Instituto Nacional de Estudos e Pesquisas Educacionais Anísio Teixeira - Inep, entre otras fuentes. Los datos indican que hay una enorme privatización de este nivel educativo y una gran diversidad de instituciones y cursos. Los recursos financieros invertidos en la educación pública alcanzan 5,3\% del Producto Interno Bruto (PIB), lo que resulta en un valor bajo en educación por persona en edad educacional, cuando las comparaciones son realizadas entre Brasil y varios países seleccionados.

Palabras clave: Educación superior. Expansión. Financiación.

\section{Introdução}

As políticas públicas sofreram grandes alterações no Brasil a partir dos anos de 1990. Após a promulgação da Constituição em 1988, uma nova Lei de Diretrizes e Bases da Educação foi aprovada em 1996 e foram implantadas, nesse período, medidas sob a orientação do Consenso de Washington (BATISTA, 200 1). No campo da educação superior, houve uma grande expansão do setor privado, uma maior diversificação das instituiç̃ões, a legalização das instituições privadas mercantis (SGUISSARDI, 2009) e uma estrutura de financiamento público com momentos de queda e outros de pequena elevação dos recursos financeiros, sem, no entanto, afetar o percentual do Produto Interno Bruto (PIB) aplicado na educação superior (AMARAL, 2013), como demonstraremos neste artigo.

A educação superior brasileira se apresenta, no início da primeira década dos anos 2010, com grandes desafios no que se relaciona à expansão e financiamento. A intensa expansão do setor privado, iniciada na ditadura militar e continuada nos governos de Fernando Henrique Cardoso (1 995-2002) e Luiz Inácio Lula da Silva (2003-2010), vem consolidando uma grande privatização desse nível de ensino no país, atingindo, em 2012, 27\% 
no setor público e 73\% no privado (BRASIL/MEC 2012). Essa política para ser compreendida exige uma análise sobre como esse processo foi implantado bem como o montante de recursos públicos investidos nesse nível de ensino e sua relação com a necessidade de acesso da população brasileira à educação superior.

Neste texto, iniciamos apresentando dados relativos à expansão da educação superior no Brasil, implementada de 1964 a 2010, quando termina o segundo mandato de Luiz Inácio Lula da Silva, com ênfase para o crescimento das instituições e das matrículas no setor público e no setor privado. A finalidade será identificar como a política para a educação superior favoreceu a privatização nesse período da história do país e as consequências dessa política para o atendimento dos jovens brasileiros de 18 a 24 anos.

Em seguida, discutimos como se realiza o financiamento da educação superior brasileira, abordando as seguintes vertentes: os recursos totais aplicados na educação brasileira como percentual do PIB, tecendo comparações com diversos países; os recursos financeiros das Instituições de Ensino Superior (IES), tanto públicas quanto privadas, detalhando como são as suas receitas e despesas, realizadas no ano de 2012 , utilizando-se informações dos microdados do Censo da Educação Superior² (BRASIL/MEC, 201 2a) e o financiamento da educação no Brasil no ambiente do Plano Nacional de Educação (PNE) para o período $2014-2015$ (BRASIL, 2014). Evidenciamos, ao longo da discussão, a necessidade da aplicação do equivalente a 10\% do PIB na educação brasileira, todos os níveis, etapas e modalidades. Finalmente, apresentaremos as conclusões deste estudo.

\section{Expansão da educação superior: a política privatista da ditadura militar ao final do governo Lula}

As políticas adotadas no Brasil para a educação superior, desde o período da ditadura militar (1964-1985), tem favorecido a expansão da oferta desse nível de ensino pelo setor privado. Alguns estudos têm destacado a privatização do ensino superior brasileiro como parte da política de cunho expansionista adotada pelo Estado, sobretudo a partir de 1964³. Segundo Cunha (1989), essa política se materializa tanto na privatização do ensino superior público, quanto na participação estatal na manutenção do ensino 
A educação superior no Brasil: os desafios da expansão e do financiamento e comparações com outros países

privado, por meio de subsídios estatais, diretos e indiretos, representados por bolsas de estudos e isenção fiscal. Como resultado desse processo de privatização intensa até 2012, somente 15,8\% dos jovens com idade de 18 a 24 anos conseguiram acesso ao ensino superior, pela impossibilidade de as famílias brasileiras pagarem por esse nível educacional.

Consideramos importante ressaltar que, do período colonial até a proclamação da República, todo o ensino superior brasileiro era público-estatal, controlado e mantido pelo poder central do Estado. Com a instituição do regime republicano, em 1889, sob a influência de liberais e positivistas, a Constituição republicana de 1891 elimina o monopólio do poder central e descentraliza a educação superior permitindo o aparecimento de instituições privadas e estaduais. Desde então, ocorreu o crescimento e a complexificação do ensino superior brasileiro, pela criação e manutenção de faculdades, nos estados, tanto por iniciativa do Governo Federal, quanto por agentes privados, confessionais e/ou empresariais (CUNHA, 1985, 1989, 1999). Em 1920, foi criada a primeira Universidade no país - a Universidade do Rio de Janeiro ${ }^{4}$, pela junção de faculdades isoladas, mas o sistema continuou diversificado, com predominância de instituições isoladas, em especial, no setor 98 privado (FÁVERO, 1989).

Com a tomada do poder pelos militares, as mudanças do ensino superior foram concretizadas na Lei n⿳ 5.540, de 28 de novembro de 1968, definindo a Reforma Universitária de então. $\bigcirc$ ensino superior privado teve facilitado o seu crescimento, a um ritmo acelerado, na década de 1970. Entre os fatores que contribuíram para esse crescimento, destacamos a predominância dos defensores do ensino privado no Conselho Federal de Educação - CFE lque flexibilizaram as normas para a criação de cursos, ampliação de vagas e concessão do status de universidade) e os subsídios governamentais, instituídos para esse setor, por meio de transferência de recursos, a fundo perdido e a juros negativos, ou mediante o crédito educativo.

Para Fonseca (1992), as modificações ocorridas, nos campos político e econômico, no período da ditadura militar, tiveram como consequência a implementação de um projeto de desenvolvimento baseado no capital externo. Para dar sustentação a tal projeto, foi definida uma política educacional que pudesse assegurar a dominação, o controle social, e, ao mesmo tempo, garantir a formação de mão de obra para o setor produtivo, sem a utilização de grandes recursos públicos. Nesse sentido, tornou-se necessário desenvolver 
uma política de expansão do ensino superior, pela via da privatização, aliviando o Estado de grandes investimentos em educação.

Os dados a seguir, expostos na Tabela 1, mostram o processo de expansão do ensino superior privado no Brasil com início da ditadura militar no ano de 1964 que se estendeu por vinte anos; em seguida, analisamos a primeira década da redemocratização no país, após o fim do regime militar e os períodos dos governos de Fernando Henrique Cardoso (1995-2002) e de Luiz Inácio Lula da Silva (2003-2010).

\section{Tabela 1}

Evolução das IES e das matrículas da educação superior brasileira, por categoria administrativa (pública e privada) - 1964/2010

\begin{tabular}{|c|c|c|c|c|c|c|c|c|c|c|}
\hline \multirow{2}{*}{ Ano } & \multicolumn{5}{|c|}{ Número de Instituições } & \multicolumn{5}{c|}{ Número de Matrículas } \\
\cline { 2 - 13 } & Total & Públ. & $\%$ & Priv. & $\%$ & Total & Públ. & $\%$ & Priv. & $\%$ \\
\hline 1964 & $372^{*}$ & $129^{*}$ & 34,7 & $243^{*}$ & 65,3 & 142 & 87 & 61,6 & 54 & 38,4 \\
\hline 1974 & $860^{* *}$ & $215^{* *}$ & 25,0 & $645^{* *}$ & 75,0 & 937 & 341 & 36,4 & 596 & 63,5 \\
\hline 1984 & 847 & 238 & 28,1 & 609 & 71,9 & 1.399 & 571 & 40,9 & 827 & 59,1 \\
\hline 1994 & 851 & 218 & 25,6 & 633 & 74,4 & 1.661 & 690 & 41,6 & 970 & 58,4 \\
\hline 2002 & 1.637 & 195 & 11,9 & 1.442 & 88,1 & 3.479 & 1.051 & 30,2 & 2.428 & 69,8 \\
\hline 2010 & 2.378 & 278 & 11,7 & 2.100 & 88,3 & 6.379 & 1.642 & $\ldots$ & 4.735 & 74,3 \\
\hline $1964-1974 \%$ & 131,2 & 66,7 & $\ldots$ & 165,4 & $\ldots$ & 559,9 & 292 & $\ldots$ & $1.003,7$ & $\ldots$ \\
\hline $1974-1984 \%$ & $-1,5$ & 10,7 & $\ldots$ & $-5,6$ & $\ldots$ & 49,3 & 67,4 & $\ldots$ & 38,8 & $\ldots$ \\
\hline $1964-1984 \%$ & 127,7 & 84,5 & $\ldots$ & 150,6 & $\ldots$ & 885,2 & 556,3 & $\ldots$ & $1.431,5$ & $\ldots$ \\
\hline $1984-1994 \%$ & 0,5 & $-8,4$ & $\ldots$ & 3,9 & $\ldots$ & 18,7 & 20,8 & $\ldots$ & 17,3 & $\ldots$ \\
\hline $1994-2002 \%$ & 92,4 & $-10,6$ & $\ldots$ & 127,8 & $\ldots$ & 109,5 & 52,3 & $\ldots$ & 150,3 & $\ldots$ \\
\hline $2002-2010 \%$ & 45,3 & 42,6 & $\ldots$ & 45,6 & $\ldots$ & 83,4 & 56,2 & & 95,0 & \\
\hline
\end{tabular}

Fontes | 1964 a 1974 (SIQUEIRA, 2006); 1984 (MARTINS, 1991); 1994 a 2010 (BRASIL/ MEC/INEP, 1994, 2002, 2010)

Nos dez primeiros anos do regime militar, de 1964 a 1974 aconteceu a maior expansão privada no país. Em 1964, o sistema era composto por 243 IES privadas e 129 IES públicas, passando, em 1974, para 645 IES privadas e 215 públicas, um crescimento percentual de 66,7\% de IES públicas contra 165,4\% das instituições privadas. Em relação a matrículas, os dados 
A educação superior no Brasil: os desafios da expansão e do financiamento e comparações com outros países

mostram que, em 1964, o ensino superior brasileiro contava com um total de 142.386 estudantes matriculados no ensino superior, dos quais 87.665 localizavam-se no sistema público e 54.721 no setor privado, ou seja, uma proporção de $61,6 \%$ das matrículas em instituições públicas e 38,4\% nas privadas. Já em 1974, o sistema passa a ter um total de 937.593 matrículas, sendo, deste total, 341.028 no setor público e 596.565 no setor privado, invertendo a proporção existente em 1964 passando o predomínio das matrículas no setor privado $(63,6 \%)$ em detrimento do setor público $(36,4 \%)$.

Na segunda década do regime militar, o crescimento do ensino superior no país foi ínfimo, sendo negativo $(-1,5 \%)$ em relação ao número total de instituições de ensino superior. Destacamos um crescimento positivo de IES públicas em 10,7\% e um decréscimo das IES privadas em -5,6\%. Em relação às matrículas, ocorreu uma pequena expansão, num total de $49,3 \%$, sendo maior no setor público $(67,4 \%)$ que no setor privado $(38,8 \%)$. Considerando todo o período da ditadura militar no Brasil, os dados evidenciam uma expansão de $127,7 \%$ do número de IES, sendo $84,5 \%$ no setor público e 150,6\% no setor privado. As matrículas apresentaram uma expansão extraordinária, totalizando $885,2 \%$ no período, sendo 556\% no setor público e 1.431,5\% no 100 setor privado.

A primeira década após o fim da ditadura militar (1984-1994) foi o período quando o sistema de ensino superior apresentou a menor expansão com apenas $0,5 \%$ de crescimento no número de IES e 18,7\% das matrículas. Chamamos atenção para o fato de ter ocorrido uma redução de $8,4 \%$ do número de IES públicas, no entanto, as matrículas, nesse setor, cresceram 20,8\% enquanto o setor privado apresentou um crescimento de matrículas menor de 17,3\%. Ressaltamos que, nessa década, a economia do país vivenciava altos índices inflacionários e foram implantados diversos planos econômicos que fracassaram e a crise econômica foi aprofundada.

No início dos anos 1990, a doutrina neoliberal passou a direcionar a política brasileira. Foi, no entanto, a partir dos governos de Fernando Henrique Cardoso (1995-2002) que essa política se acentuou por meio de uma série de reformas no Estado, tendo a privatização como um dos eixos centrais. Os pressupostos básicos da reforma do Estado no Brasil estão especificados no Plano Diretor da reforma do aparelho do Estado, publicado em novembro de 1995, que "[...] define objetivos e estabelece diretrizes para a reforma da administração pública brasileira" (BRESSER PEREIRA; SPINK, 1998, p. 186). 
Na educação superior, a reforma implantada seguiu as diretrizes dos organismos internacionais, cuja tese é a de que o sistema de ensino superior, deve se tornar mais diversificado e flexível, objetivando uma expansão com contenção nos gastos públicos ${ }^{5}$. Essa reforma foi implementada por meio da edição de uma série de instrumentos normativos, tendo, como marco de referência, a Lei de Diretrizes e Bases da Educação Nacional - LDB, Lei n 9.394, aprovada em 20 de dezembro de 1996, quando o Estado assumiu papel destacado no controle e na gestão das políticas educacionais. Dentre as diversas alterações adotadas na educação superior brasileira a partir da LDB, merece destaque o art. 20 que estabelece a existência de dois tipos de instituições privadas de ensino: as lucrativas (empresariais) e não lucrativas (comunitárias; confessionais e filantrópicas). A aprovação da LDB favoreceu não apenas a expansão das instituições ditas não lucrativas, mas também o setor empresarial que almeja o lucro e a acumulação do capital, como podemos evidenciar nos dados apresentados na Tabela 1 .

Como resultado da implementação dessa política, o setor público apresentou um decréscimo em relação ao número de instituições de 10,6\% enquanto as IES privadas cresceram 127,8\% no período de 1994 a 2002. As matrículas totalizaram um crescimento de $109,5 \%$, sendo $52,3 \%$ no setor público e 150,3\% no setor privado, aprofundando a expansão privada do ensino superior no país. No início do governo de Fernando Henrique Cardoso, a proporção de matrículas era de $41,6 \%$ no setor público contra 58,6\% no setor privado. Em 2002, as matrículas, no setor privado, passaram a representar $69,8 \%$ contra 30,2\% de matrículas públicas.

A política de favorecimento da expansão do setor privado tem continuidade nos governos de Luiz Inácio Lula da Silva (2003 a 2010), apesar de apresentar índices de crescimento menores que o governo anterior. As IES expandiram 45,3\%, sendo que as privadas cresceram $45,6 \%$ e as públicas $42,6 \%$, acentuando a privatização no país. Em 2010, o setor privado representava $88,3 \%$ de IES e as públicas, apenas, 11,7\%. As matrículas apresentaram um crescimento maior, atingindo um total de $83,4 \%$, no período, sendo que as matrículas públicas cresceram $56,9 \%$ e as privadas $95,0 \%$. Dos 6,3 milhões de jovens matriculados em cursos de graduação presencial e a distância no Brasil em 2010; 4,7 milhões estavam em IES privadas, representando 74,3\% e, 1,6 milhões matriculados em IES públicas, representando 25,7\% do total de matrículas no país. 
Essa política de privatização adotada no Brasil coloca o país com a segunda maior privatização desse nível de ensino no conjunto de 15 países da América Latina, com 73\% dos estudantes matriculados em IES privadas (dados de 20121, só perdendo para o Chile cuja totalidade do ensino superior está privatizada, como mostramos no Gráfico 1, a seguir, em que a informação do Brasil é de 2008.

Os países que apresentam os menores índices de privatização da educação superior desse conjunto de países da América Latina são Uruguai, Argentina e Bolívia. Nesses países, a maioria dos estudantes está matriculada em instituições públicas de educação superior, com 84,5\% no Uruguai, 73,2\% na Argentina e 70,4 \% na Bolívia.

\section{Gráfico 1}

Distribuição dos estudantes de nível superior/universitário, por setor administrativo, em 15 países da América Latina, 2009

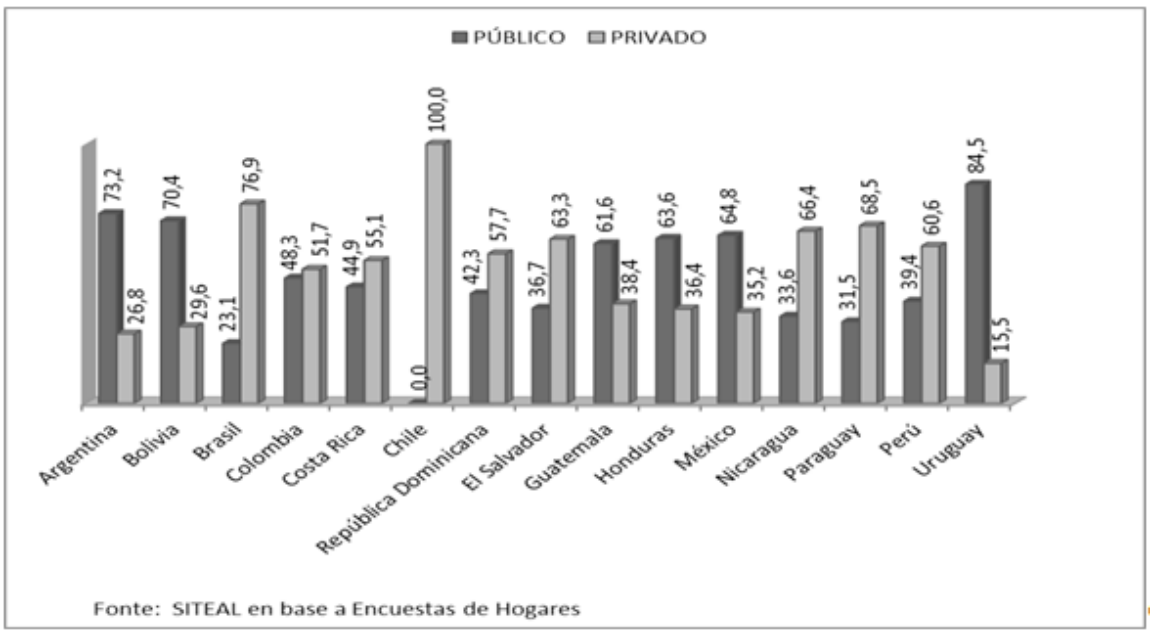

Uma das consequências dessa política de expansão de privatização efetivada no Brasil, por meio do crescimento numérico das IES privadas, em especial as instituições empresariais (com fins lucrativos) se reflete no acesso ao ensino superior dos jovens de 18 a 24 anos. O estudo da educação dos jovens com idade entre 18 e 24 anos se reveste de grande complexidade. $\bigcirc$ estudante, ao terminar o ensino médio, deve decidir por um dos seguintes caminhos: 
realização de algum curso superior de graduação, obter uma formação profissional, ou inserir-se imediatamente no mercado de trabalho, interrompendo suas atividades educacionais. Entretanto, a defasagem idade-série fez com que, no Brasil, 14 milhões de jovens com idade entre 18 e 24 anos necessitem de uma educação para completar 12 anos de estudos - o que corresponderia a concluir o ensino médio (PINTO, 201 1). Quando realizam o ensino superior, afirma-se que há universalização desse nível educacional quando se tem mais de $50 \%$ dos jovens nessa faixa de idade matriculados na educação superior (GOMES, 2002).

Brasil está muito distante dessa meta e somente, em 2012, venceu a barreira da elitização, quando esse percentual superou os $15 \%$. A massificação também está distante, o que ocorre quando esse percentual é superior a 30\%. $O$ quantitativo de jovens com idade entre 18 e 24 anos no Brasil, em 2012, era de 22.471.385, segundo dados da Pesquisa Nacional por Amostra de Domicílios (PNAD) (BRASIL/IBGE, 2012). Desses jovens, 3.559.010 estavam matriculados na educação superior, o que resulta em uma taxa líquida de 15,8\%, o que classifica a educação superior brasileira como aquela que acabou de vencer o elitismo nesse nível educacional.

Os dados apresentados, nesse estudo, possibilitam afirmar que a política de privatização da educação superior no Brasil reflete, de um lado, a omissão dos governos em relação à expansão do setor público, criando uma reserva de mercado para o setor privado. Por outro lado, é recorrente a liberalização e desregulamentação desse setor que tem encontrado facilidades para expandir, por meio da adoção pelo Estado brasileiro de uma série de mecanismos, tais como: a liberalização dos serviços educacionais, isenções tributárias, isenção da contribuição previdenciária das filantrópicas, isenção do salário educação, bolsas de estudo para alunos carentes via programa do Crédito Educativo hoje transformado no Fundo de Financiamento ao Estudante de Ensino Superior $(\mathrm{Fies})^{6}$, empréstimos financeiros a juros baixos por instituições bancárias oficiais como o Banco Nacional de Desenvolvimento Econômico e Social-BNDES, o Programa Universidade para Todos - Prouni ${ }^{7}$, dentre outras formas de estímulo, fortalecendo o setor privado, como evidenciamos a seguir. 
A educação superior no Brasil: os desafios da expansão e do financiamento e comparações com outros países

\section{Os recursos financeiros totais aplicados na educação brasileira}

A Constituição Federal brasileira de 1988 estabeleceu vinculações mínimas dos impostos nos âmbitos federal, estaduais, do Distrito Federal (DF) e municipais que devem, obrigatoriamente, ser aplicados em educação, todos os níveis, etapas e modalidades. A aplicação apenas do percentual mínimo tem levado à utilização de volumes de recursos financeiros em percentuais em torno de $5 \%$ do PIB. Esse limite percentual é detectado tanto em estudos teóricos (NEGRI, 1997; PINTO, 2001 ; AMARAL, 2003; CASTRO, 2005) quanto em valores apurados a partir dos relatórios contábeis que explicitam a execução das despesas realizadas pela União, pelos Estados, pelo Distrito Federal e pelos Municípios, sendo divulgados pelo MEC (BRASIL/MEC 2011 ).

A aplicação do equivalente a um percentual em torno de 5\% do PIB em educação pública resulta em um baixo valor por pessoa em idade educacional (0 a 24 anos), quando comparações são realizadas com países selecionados (AMARAL, 2011 ). A tabela 2 apresenta os valores aplicados por pessoa em idade educacional em diversos países selecionados, utilizando dados que constam do The World Factbook 2010 da Central Intelligence Agency (CIA)

104 dos EUA em que os PIBs são considerados com as correções que fazem a paridade do poder de compra (Purchasing Power Parity). A informação do The World Factbook para o Brasil é que, em 2010, lúltimo ano divulgado neste banco de dados, para o Brasil) foi aplicado o equivalente a 5,8\% do PIB em educação pública (EUA, 2015).

\section{Tabela 2}

Recursos financeiros aplicados por pessoa em idade educacional

\begin{tabular}{|c|c|c|c|c|c|}
\hline País & $\begin{array}{c}\text { \% PIB em } \\
\text { Educação } \\
(2008)\end{array}$ & $\begin{array}{c}\text { PIB/PPP } \\
\text { (US\$ bi) }\end{array}$ & $\begin{array}{c}\text { Valor aplicado } \\
\text { em educação } \\
\text { ( US\$ bi) }\end{array}$ & $\begin{array}{c}\text { População em } \\
\text { idade educacional }\end{array}$ & $\begin{array}{c}\text { US\$ por pessoa em } \\
\text { idade educacional }\end{array}$ \\
\hline Yemen & 5,2 & 62 & 3,2 & 16.361 .263 & 197 \\
\hline Índia & 3,2 & 4.990 & 159,7 & 576.136 .598 & 277 \\
\hline Paraguai & 4,8 & 46 & 2,2 & 3.130 .703 & 705 \\
\hline Bolívia & 6,9 & 59 & 4,1 & 5.645 .319 & 721 \\
\hline Indonésia & 2,8 & 1285 & 36,0 & 109.812 .975 & 328 \\
\hline China & 1,9 & 13.390 & 254,4 & 431.110 .239 & 590 \\
\hline Brasil & 5,8 & 2.416 & 140,1 & 81.670 .686 & 1.716 \\
\hline
\end{tabular}


Vera Lúcia Jacob Chaves | Nelson Cardoso Amaral

\begin{tabular}{|c|c|c|c|c|c|}
\hline País & $\begin{array}{l}\% \text { PIB em } \\
\text { Educação } \\
(2008)\end{array}$ & $\begin{array}{l}\mathrm{PIB} / \mathrm{PPP} \\
\text { (US\$ bi) }\end{array}$ & $\begin{array}{c}\text { Valor aplicado } \\
\text { em educação } \\
\text { ( US \$ bi) }\end{array}$ & $\begin{array}{c}\text { População em } \\
\text { idade educacional }\end{array}$ & $\begin{array}{l}\text { US\$ por pessoa em } \\
\text { idade educacional }\end{array}$ \\
\hline Botswana & 9,5 & 34 & 3,2 & 1.174 .902 & 2.749 \\
\hline $\begin{array}{c}\text { África do } \\
\text { Sul }\end{array}$ & 6 & 596 & 35,8 & 23.462 .188 & 1.524 \\
\hline Cuba & 12,2 & 121 & 14,8 & 3.303 .128 & 4.469 \\
\hline México & 5,1 & 1.845 & 94,1 & 55.331 .861 & 1.701 \\
\hline Argentina & 6,3 & 771 & 48,6 & 17.467 .896 & 2.781 \\
\hline Chile & 4,5 & 335 & 15,1 & 6.424 .641 & 2.346 \\
\hline Uruguai & 4,5 & 56 & 2,5 & 1.233 .200 & 2.043 \\
\hline Rússia & 4,1 & 2.553 & 104,7 & 38.609 .444 & 2.711 \\
\hline Portugal & 5,6 & 243 & 13,6 & 2.952 .177 & 4.609 \\
\hline $\begin{array}{c}\text { Coréia do } \\
\text { Sul }\end{array}$ & 5 & 1.666 & 83,3 & 13.535 .036 & 6.154 \\
\hline França & 5,9 & 2.276 & 134,3 & 20.275 .258 & 6.623 \\
\hline $\begin{array}{l}\text { Dina- } \\
\text { marca }\end{array}$ & 8,7 & 211 & 18,4 & 1.676 .292 & 10.951 \\
\hline Canadá & 5,4 & 1.518 & 82,0 & 9.823 .425 & 8.345 \\
\hline Espanha & 5 & 1.389 & 69,5 & 11.934 .485 & 5.819 \\
\hline Austrália & 5,6 & 998 & 55,9 & 7.044 .884 & 7.933 \\
\hline Alemanha & 5,1 & 3.227 & 164,6 & 19.115 .218 & 8.610 \\
\hline Japão & 3,8 & 4.729 & 179,7 & 29.106 .676 & 6.174 \\
\hline $\begin{array}{l}\text { Estados } \\
\text { Unidos }\end{array}$ & 5,4 & 16.720 & 902,9 & 105.553 .286 & 8.554 \\
\hline Áustria & 5,9 & 361 & 21,3 & 2.072 .212 & 10.278 \\
\hline Norvega & 6,9 & 282 & 19,5 & 1.611 .259 & 12.076 \\
\hline
\end{tabular}

Fontes |(EUA, 2015) para a 1a, 2a e 4a colunas e cálculos deste estudo

Com exceção de Cuba, que aplicou US $\$ 4.469,00$ por pessoa em idade educacional, os outros países constantes da tabela 2, do Yemen até a Rússia, aplicaram, no máximo, US\$2.749,00, que foi o caso de Botswana. O Brasil aplicou US\$ 1.716,00 por pessoa em idade educacional. Os outros países da tabela, de Portugal à Norvega aplicaram valores muito mais elevados, sendo que a média desses países resultou em US\$8.01 1,00. A média de todos os países em análise foi de US $\$ 4.481,00$.

$\bigcirc$ Brasil, aplicando, apenas, US\$1.716,00 por pessoa em idade educacional tem um enorme desafio para atingir, por exemplo, o valor médio de todos os países selecionados, que foi de US\$ 4.481,00. Atingir esse valor 
A educação superior no Brasil: os desafios da expansão e do financiamento e comparações com outros países

significaria multiplicar por 2,61 o valor apurado na tabela 2, o que implicaria aplicar o equivalente a $15 \%$ do PIB de recursos financeiros em educação.

\section{O financiamento da educação superior brasileira}

A educação superior brasileira, altamente privatizada, como já vimos, é financiada tanto pelos recursos do fundo público, parte dos recursos discutidos no item anterior, quanto pelo pagamento de mensalidades, que são recursos das famílias, e por recursos oriundos da interação das instituições com os diversos setores da sociedade - empresas, indústrias, associações etc. Essa tríade de possibilidades de fontes de recursos financeiros é permitida pela Constituição Brasileira ao afirmar, em seu artigo 205, que "A educação, direito de todos e dever do Estado e da família será promovida e incentivada com a colaboração da sociedade [...]" (BRASIL, 1988)

Apresentaremos um panorama do financiamento das instituições de educação superior (IES) brasileiras tomando, como referência, o ano de 2012 , considerando os recursos públicos e privados utilizados no pagamento das

106 despesas das instituições e os custos dos alunos que estudam nas diferentes esferas administrativas: federal, estadual, municipal e privada. Devemos observar que, na esfera federal, estão incluídas todas as instituições que oferecem cursos superiores, como as Instituições Federais de Ensino Superior (IFES) e instituições que oferecem os cursos tecnológicos.

Os dados financeiros das IES brasileiras apurados pelo Inep, por meio do Censo da Educação Superior, no ano de 2012 (BRASIL/MEC, 2012a) estão sistematizados na Tabela 3. Cabe-nos comentar que esses dados são fornecidos pelas próprias instituições e, portanto, não há a garantia de que eles correspondam aos valores reais. De qualquer forma, na falta de outras fontes, eles nos fornecem uma primeira aproximação de um universo ainda pouco conhecido.

Os dados da Tabela 3 revelam que: a) os recursos que financiam as atividades das instituições federais são, em sua maior parte, originários da União, 87,46 \%; b) as instituições estaduais recebem recursos dos estados $(87,43 \%) ; c)$ as instituições municipais recebem recursos dos municípios $(4,82 \%)$, sendo que os recursos oriundos de mensalidades atingem o elevado 
percentual de $92,72 \%$ d d) as instituições privadas são financiadas quase que exclusivamente pelos recursos oriundos das mensalidades $(90,12 \%)$.

\section{Tabela 3}

Fonte de receitas das IES por origem dos recursos e natureza das instituições, 2012

\begin{tabular}{|c|c|c|c|c|}
\hline Fonte do Recurso & Federal \% & Estadual \% & Municipal \% & Privadas \% \\
\hline Arrecadação Própria & 5,97 & 10,87 & 92,72 & 90,12 \\
\hline $\begin{array}{c}\text { Transferência de mantenedoras } \\
\text { (governos dos entes federados, } \\
\text { no caso das públicas e propri- } \\
\text { etários, no caso das privadas) }\end{array}$ & 87,46 & 87,43 & 4,82 & 0,82 \\
\hline Outros Recursos & 6,56 & 1,70 & 2,46 & 9,06 \\
\hline & 100,00 & 100,00 & 100,00 & 100,00 \\
\hline
\end{tabular}

Fontel Microdados do Censo da Educação Superior de 2012 (BRASIL/MEC, 2012a)

É preciso considerar ainda que uma expressiva quantidade de recursos não incluídos nos orçamentos da instituições é intermediada entre as IES e as fundações privadas de "apoio", e que não são possíveis de ser estimados pela falta de mecanismos administrativos que acompanhem a execução dos orçamentos dessas fundações.

As despesas declaradas pelas IES, e apuradas pelo Censo da Educação Superior, são apresentadas na Tabela 4. Elas revelam que: a) as instituições federais gastaram cerca de 60 \% dos seus recursos com o pagamento de pessoal, sendo que as despesas de outros custeios atingiram 22,1\% e as de capital, 10,2\%; as instituições estaduais aplicaram cerca de 66,8\% dos seus recursos no pagamento de pessoal, 19,4\% no pagamento de outros custeios e 9,0\% nas despesas de capital; c) as instituições municipais gastaram cerca de $69,5 \%$ de seus recursos com o pagamento de pessoal, 19,8\% com o pagamento de outros custeios e 4,0\% para capital; d) as instituições privadas destinaram cerca de 55,6\% para o pagamento de pessoal, 23, $1 \%$ para outros custeios e 6,2\% para capital. 
A educação superior no Brasil: os desafios da expansão e do financiamento e comparações com outros países

\section{Tabela 4}

Despesas das IES classificadas por natureza econômica e tipo de instituição 2012

\begin{tabular}{|l|l|l|l|l|}
\hline Despesas Realizadas & Federal \% & Estadual \% & Municipal \% & Privadas \% \\
\hline Despesas de Pessoal & 60,0 & 66,8 & 69,5 & 55,6 \\
\hline $\begin{array}{l}\text { Despesas de Outros } \\
\text { Custeios }\end{array}$ & 22,1 & 19,4 & 19,8 & 23,1 \\
\hline Despesas de Capital & 10,2 & 9,0 & 4,0 & 6,2 \\
\hline Outras despesas & 7,8 & 4,8 & 6,7 & 15,2 \\
\hline Total & 100 & 100 & 100 & 100 \\
\hline
\end{tabular}

Fontes | Microdados do Censo da Educação Superior de 2012; (BRASIL/MEC, 20 1 2a)

Observamos que o percentual aplicado em pessoal varia de 55,6\% nas privadas para $69,5 \%$ nas estaduais. Nas federais, o percentual foi de $60,0 \%$, sendo que, nessas instituições, o pagamento de inativos e pensionistas significa um elevado percentual médio da ordem de 24\% (AMARAL, 2003). Estas são despesas previdenciárias que deveriam ser contabilizadas na despesa federal com essa subfunção, e não como despesa das IES federais.

Verificamos, ainda, que o percentual das despesas totais que é aplicado em despesas de capital é menor nas federais, estaduais e municipais que nas IES privadas.

As despesas realizadas pelas IES brasileiras, no ano de 2012 , atingiram o montante de $\mathrm{R} \$ 106,88$ bilhões. Esse montante representa um volume de recursos financeiros equivalente a $2,43 \%$ do PIB de 2012, que foi de $R \$$ 4,392 trilhões.

Como indicam os dados apresentados na Tabela 5, os recursos aplicados pelas IES públicas totalizaram R \$ 61,09 bilhões, o que representou 1,39\% do PIB em 2012 e as IES privadas aplicaram um total de R \$ 45,80 bilhões, o que representou 1,04\% do PIB.

\section{Tabela 5}

Despesas realizadas pelas IES brasileiras em 2012 como percentuais do PIB

\begin{tabular}{|c|c|c|}
\hline Categoria Administrativa & Despesas & $\%$ PIB \\
\hline Federal & $40.635 .268 .381,00$ & 0,93 \\
\hline Estadual & $19.881 .063 .246,00$ & 0,45 \\
\hline
\end{tabular}


Vera Lúcia Jacob Chaves | Nelson Cardoso Amaral

\begin{tabular}{|c|c|c|}
\hline Categoria Administrativa & Despesas & $\%$ PIB \\
\hline Municipal & $569.879 .572,00$ & 0,01 \\
\hline Total Pública & $61.086 .211 .199,00$ & 1,39 \\
\hline Privadas & $45.796 .957 .026,00$ & 1,04 \\
\hline Total Privada & $45.796 .957 .026,00$ & 1,04 \\
\hline Total Geral & $106.883 .168 .225,00$ & 2,43 \\
\hline
\end{tabular}

Fonte | Microdados do Censo da Educação Superior de 2012 ; (BRASIL/MEC, 201 2a)

Um detal hado estudo analisando o custo dos estudantes (AMARAL; PINTO, 2010), que retira a follha de pagamento de aposentados e recursos que financiam pesquisa e extensão, apresenta uma metodologia que utilizaremos aqui para o cálculo do custo médio do aluno de graduação em 2012. Nesse ano de 2012, os microdados do Censo da Educação Superior não apresentaram a informação sobre o pagamento de aposentados e, portanto, a Tabela 6 apresenta o custo médio do aluno sem retirar esse pagamento das IES, o que é substancial para as instituições federais, pois superestima o custo do aluno dessas instituições.

\section{Tabela 6}

\section{Custo médio do aluno de graduação por natureza das IES - 2012 (Valores em R\$)}

\begin{tabular}{|c|c|c|c|}
\hline & $\begin{array}{c}\text { Recursos financeiros } \\
\text { destinados ao ensino } \\
\text { de graduação }(R \$)\end{array}$ & $\begin{array}{c}\text { Total de alunos de graduação } \\
\text { presenciais, EAD e de pós- } \\
\text { graduação stricto-sensu }\end{array}$ & $\begin{array}{c}\text { Custo médio do aluno } \\
\text { de graduação (R\$) }\end{array}$ \\
\hline Federal & $18.395 .166 .847,00$ & 1.235 .543 & $14.888,33$ \\
\hline Estadual & $12.079 .489 .313,00$ & 697.689 & $17.313,57$ \\
\hline Municipal & $515.196 .964,00$ & 185.998 & $2.769,91$ \\
\hline Privadas & $41.707 .457 .552,00$ & 5.183 .225 & $8.046,62$ \\
\hline
\end{tabular}

Fonte | Microdados do Censo da Educação Superior de 2012 ; (BRASIL/MEC, 2012 a); (AMARAL; PINTO, 2010)

As estimativas para o custo do aluno das IES, apresentadas na tabela anterior, indicam, com exceção das IES municipais, que não há grandes diferenças entre as instituições. Os custos médios mais elevados se encontram nas instituições estaduais e federais. Esse resultado pode ser analisado pela maior homogeneidade existente nesse sistema, abrigando uma isonomia de carreira e salários, alto percentual de docentes trabalhando em regime de dedicação 
A educação superior no Brasil: os desafios da expansão e do financiamento e comparações com outros países

exclusiva, oferta de cursos nas diversas áreas do conhecimento e desenvolvimento de atividades tecnológicas, culturais e na área de saúde da população por meio dos hospitais universitários, que estão pouco presentes nas outras esferas administrativas.

\section{O financiamento da educação brasileira no contexto do PNE (2014-2024)}

Estudos realizados pelo Instituto Brasileiro de Geografia e Estatística (IBGE) mostram que há em evolução no Brasil uma dinâmica populacional que estabilizará o total da população e diminuirá a quantidade de crianças e jovens em idade educacional.

O Plano Nacional de Educação (PNE), aprovado pela Lei No 13.005 de 15 de junho de 2014, apresenta 20 metas a serem cumpridas até 2024, sendo que, em algumas delas, estabelecem objetivos a serem atingidos até o ano de 2016 (BRASIL, 2014). A Tabela 7 mostra a evolução do quantitativo populacional nas diversas faixas etárias educacionais, nos anos de 2014 ,

110 início do PNE, no ano de 2016 , intermediário, e 2024, ano final do plano. Utilizamos os dados do estudo realizado pelo IBGE que mostra a projeção annual da dinâmica populacional brasileira até 2060 (BRASIL/IBGE, 20 14).

\section{Tabela 7}

Dinâmica populacional em idade educacional no período do PNE (2014-2024)

\begin{tabular}{|c|c|c|c|}
\hline Nível/Etapa da educação & 2014 & 2016 & 2024 \\
\hline Creche & 11,9 & 11,6 & 10,5 \\
\hline $\begin{array}{c}\text { Educação Infantil - 4 a 5 } \\
\text { anos }\end{array}$ & 6,1 & 6,0 & 5,4 \\
\hline $\begin{array}{c}\text { Ensino Fundamental } \\
\text { Ensino Médio }\end{array}$ & 29,6 & 29,2 & 26,1 \\
\hline Educação Superior & 23,9 & 10,3 & 9,4 \\
\hline $\begin{array}{c}\text { Total da população em } \\
\text { idade educacional }\end{array}$ & 81,8 & 80,1 & 74,9 \\
\hline $\begin{array}{c}\text { Fonte | (BRASIL/IBGE, 20 14) } \\
\text { (BRA }\end{array}$ & & \\
\hline
\end{tabular}


Notamos, portanto, que não há grande diminuição da população em idade educacional no período 2014 a 2024, período do PNE. Os jovens com idade entre 18 e 24 anos (educação superior) serão aqueles que praticamente não sofrerão uma redução; o quantitativo de crianças em idade do Ensino Fundamental sofrerá a maior redução. Dessa forma, a próxima década será decisiva na educação brasileira e as decisões políticas precisarão ser ousadas e destinar elevados recursos financeiros ao setor da educação, sendo que, a partir das próximas décadas, a própria dinâmica populacional colaborará para que os problemas educacionais brasileiros sejam diminuídos. Devemos considerar, ainda, nesse contexto, que haverá uma grande redução da força de trabalho jovem brasileira (AMARAL, 2011 ).

Ministério da Fazenda realizou estudos prospectivos sobre a evolução do PIB até o ano de 2044, estabelecendo percentuais de crescimento, ano a ano. A Tabela 8 apresenta esses percentuais e, ainda, a evolução do PIB (em US \$ bilhões) no período $2014-2024$. Devemos ressaltar que as projeções do Ministério da Fazenda com relação à elevação do PIB não estão conseguindo acertar o que ocorre na realidade. No ano de 2014 , por exemplo, a previsão era de um crescimento de 3,07\% e a realidade mostrou um crescimento muito próximo de zero (BRASIL/IBGE, 2015).

Tabela 8

Evolução do PIB do Brasil - 2014 a 2024

\begin{tabular}{|c|c|c|}
\hline Ano & \% crescimento do PIB & PIB (US\$ trilhões) \\
\hline 2014 & 3,07 & 2,591 \\
\hline 2015 & 2,87 & 2,665 \\
\hline 2016 & 2,86 & 2,741 \\
\hline 2017 & 2,91 & 2,821 \\
\hline 2018 & 2,79 & 2,900 \\
\hline 2019 & 2,80 & 2,981 \\
\hline 2020 & 2,60 & 3,059 \\
\hline 2021 & 2,58 & 3,138 \\
\hline 2022 & 2,65 & 3,221 \\
\hline 2023 & 2,43 & 3,299 \\
\hline 2024 & 2,37 & 3,377 \\
\hline \multicolumn{2}{|c|}{ Fonte | (BRASIL/MF, 2010) } \\
\hline
\end{tabular}


A educação superior no Brasil: os desafios da expansão e do financiamento e comparações com outros países

O PNE (20 14-2024), em sua meta 20, contém o objetivo de atingir o equivalente a $10 \%$ do PIB para os recursos públicos aplicados em educação; entretanto, nesse percentual, serão contabilizados os recursos públicos tanto para o setor público como para o setor privado, seja por meio de programas de financiamento ou de bolsas a estudantes (BRASIL, 2014).

Como já examinamos, o conjunto dos países da tabela 2, aplica, em média, o equivalente a US\$4.481,00, por pessoa em idade educacional. Brasil chegaria a US\$4.459,28, mantida a aplicação do equivalente a 10\% do PIB até 2024. Isso significa que o País ainda precisará manter elevados percentuais do PIB aplicados em educação, nas décadas seguintes, para se aproximar da média dos países da Organização para a Cooperação e Desenvolvimento Econômico (OCDE), como França (US\$ 6.623,00), Alemanha (US\$ 8.610,00), Estados Unidos (US\$ 8.554,00), Áustria (US\$ 10.278,00), Dinamarca (US\$10.951,00) etc A Tabela 9 mostra a evolução para esse caso nos anos de 2014, 2016 e 2024.

\section{Tabela 9}

Evolução percentual da população em idade educacional no período do PNE (2014-2024), aplicando-se 10\% do PIB

\begin{tabular}{|c|c|c|c|c|c|}
\hline Ano & $\begin{array}{c}\text { População em } \\
\text { idade educacional } \\
\text { (em milhões) }\end{array}$ & $\begin{array}{c}\text { PIB/PPP } \\
\text { (US\$ tri) }\end{array}$ & $\begin{array}{c}\text { \% do PIB em } \\
\text { educação }\end{array}$ & $\begin{array}{c}\text { Valor em } \\
\text { educação } \\
\text { (US\$ bi) }\end{array}$ & $\begin{array}{c}\text { US\$ por pessoa em } \\
\text { idade educacional }\end{array}$ \\
\hline 2014 & 81,8 & 2,591 & 10 & 259 & $3.166,26$ \\
\hline 2016 & 80,1 & 2,741 & 10 & 274 & $3.420,72$ \\
\hline 2024 & 74,9 & 3,337 & 10 & 3334 & $4.459,28$ \\
\hline
\end{tabular}

Fonte | (EUA/CIA, 2015); (BRASIL/IBGE, 2014)

Com a computação dos recursos públicos aplicados no setor privado para atingir o equivalente a 10\% do PIB, podemos garantir que o percentual aplicado, no setor público, será um percentual que ficará em torno de 8,5\%, segundo estudos realizados pela Associação Nacional de Pesquisa em Financiamento da Educação (Fineduca) (FINEDUCA, 2014), o que poderá afetar o cumprimento das metas do PNE, uma vez que elas foram elaborados prevendo-se todo o volume de recursos aplicados diretamente no setor público. 


\section{Considerações finais}

As análises realizadas nos permitem afirmar que o Brasil é um dos países que possui grandes desafios para solucionar os problemas existentes na área educacional, uma vez que a configuração existente para a sua população em idade educacional e a sua riqueza não permite elevar substancial e abruptamente o volume de recursos financeiros para essa área social.

movimento de privatização desse nível de ensino tem sido intenso e tem favorecido a adoção de um modelo educacional que privilegia a mercantilização do ensino como a principal forma de oferta desse nível de ensino.

Os dados evidenciados, neste estudo, revelam que a política expansionista adotada, pelos governos brasileiros, desde a ditadura militar (1964) aos governos de Fernando Henrique Cardoso e Luiz Inácio Lula da Silva, por meio do aprofundamento da privatização do ensino superior, apesar de ter promovido a expansão do acesso não corresponde ainda à grande demanda populacional existente, em especial, na faixa etária de 18 a 24 anos.

Censo da Educação Superior mostra que, apenas, 15,8\% desses jovens tiveram acesso à educação superior em 2012 sendo que a maioria expressiva dos alunos matriculados no ensino superior brasileiro, 73\%, está no setor privado e, em instituições isoladas de ensino que não desenvolvem pesquisa e extensão.

Os reduzidos investimentos públicos (apenas 1,39\% do PIB, como vimos, em 2012, para a educação superior) e a defesa da diversificação das fontes de financiamento foram centrais na reforma da educação superior adotada no país desde a década de 1990. O argumento para a adoção dessa política se sustenta na tese de que o conhecimento propiciado pelo ensino superior deve ser visto como um investimento produtivo (pois garante ganhos), um bem privado ou uma mercadoria de interesse individual negociado no mercado de trocas. Isso fortalece a ideia de que o Estado deve se afastar da manutenção desse nível de ensino uma vez que a educação superior passa a ser considerada um serviço público não exclusivo do Estado e competitivo.

Desse modo, a educação de direito público e dever do Estado está sendo transformada numa atraente mercadoria a ser negociada no mercado capitalista de serviços, nacional e internacional. Ora, sem a garantia de financiamento público para o sustento integral, as IES públicas seguirão a lógica 
da gestão empresarial, perdendo a frágil autonomia que ainda possuem, na medida em que a agenda da universidade será definida com base nos interesses privados. A aprovação do PNE (20 14-2024) pelo Congresso Nacional, prevendo a aplicação do equivalente a $10 \%$ do PIB em educação, propiciará condições para uma expansão maior do setor público e amenizará a condição de heteronomia que the é imposta, apesar de se computar nesse percentual os recursos que se dirigirão ao setor privado.

Em síntese, podemos afirmar que a reforma em curso para a educação superior brasileira precisará do aporte de maior montante de recursos públicos; caso contrário, estará dificultando, ainda mais o acesso da maioria da população ao ensino superior público e de qualidade, que é um direito de todolals e deve ser garantido pelo Estado brasileiro. A formação de profissionais de alta qualidade em nível superior é uma necessidade urgente para o desenvolvimento da sociedade brasileira em que ocorra, simultaneamente, uma redução da exclusão social.

\section{Notas}

1 Este artigo apresenta resultado da Pesquisa "Política de Financiamento da Expansão da Educação Superior no Brasil - uma análise dos Planos Nacionais de Educação" financiada pelo CNPq e pela CAPES/OBEDUC.

2 Os resultados existentes, para 2013, ainda são preliminares, segundo o Inep.

3 Dentre esses estudos, destacamos os seguintes: Cunha (1985, 1986, 1989, 1999); Dourado (1999, 2000, 2001); Fávero (1989, 1991); Fonseca (1992); Martins (1988, 1991, 1997); Sguissardi (1993, 1999, 2000); Silva Júnior; Trindade (1999).

4 A Universidade do Rio de Janeiro passou a se chamar Universidade do Brasil, em 1937; teve sua autonomia estabelecida pelo Decreto-Lei n 8.393, de 17 de dezembro de 1945; foi renomeada como Universidade Federal do Rio de Janeiro, pela Lei n 4.831/65. Mobilização de professores e alunos, sobretudo ex-docentes e ex-alunos, garantiu, em vitória judicial, o retorno ao nome consagrado Universidade do Brasil, em 30 de novembro de 2000.

5 Esses dois elementos estão estabelecidos no documento La enseñanza superior - las lecciones derivadas de la experiência, publicado em 1994, pelo Banco Mundial, no qual são apresentadas as diretrizes para a reforma da educação superior, na América Latina, Ásia e Caribe. Essas diretrizes foram seguidas pelos governos de Fernando Henrique Cardoso (1995-2002) e de Luiz Inácio Lula da Silva (2003-2010) na implementação da política educacional brasileira, em especial, nas reforma da educação superior.

6 Fundo de Financiamento ao Estudante de Ensino Superior criado pela Lei $n^{\circ} 10.260$, de 12 de julho de 2001 que, no período de 1999 a 2009, disponibilizou 7,3 bilhões de reais para 
o financiamento de estudantes em Instituições de Ensino Superior privadas. (BRASIL. Ministério da Fazenda, 2010.

$7 \bigcirc$ "Programa Universidade para Todos" - Prouni - foi instituído pela Lei n 11.096 , de 13 de janeiro de 2005 e estende os benefícios fiscais para todas as IES privadas, em "troca" de preenchimento das "vagas ociosas por alunos "carentes", afrodescendentes, portadores de necessidades especiais, indígenas, ex-presidiários.

\section{Referências}

AMARAL, Nelson Cardoso. Financiamento da educação superior: Estado X mercado. São Paulo: Cortez; Piracicaba: Editora Unimep, 2003.

AMARAL, Nelson Cardoso. Os recursos financeiros aplicados nas universidades federais nos governos FHC e Lula e um olhar sobre a qualidade. In: SOUSA, José Vieira (Org.). Educação superior: cenários impasses e propostas. Campinas-SP: Autores Associados, 2013.

AMARAL, Nelson Cardoso; PINTO, José Marcelino de Rezende. $\bigcirc$ financiamento das IES brasileiras em 2005: recursos públicos, privados e custo dos alunos. Série-Estudos, Campo Grande, n. 30, p. 51-70, jul./dez. 2010.

novo PNE e o financiamento da educação no Brasil: os recursos como um percentual do PIB. In: SEMINÁRIO BRASILEIRO DE EDUCAÇÃO, 3., 2008, Campinas. Anais... Campinas: Universidade de Campinas; CEDES, 2011.

BATISTA, Paulo Nogueira. Consenso de Washington: a visão neoliberal dos problemas latino-americanos. Consulta popular. Cartilha 7. São Paulo: Expressão Popular, 2001.

BANCO MUNDIAL. La enseñanza superior: las lecciones derivadas de la experiencia. Washington, D.C: Banco Mundial, 1994.

BRASIL. Decreto-Lei n 8.393, de 17 de dezembro de 1945. Concede autonomia, administrativa financeira, didática e disciplinar, à Universidade do Brasil, e dá outras providências. Diário Oficial da União - Seção 1 - 20/12/1945. Disponível em: http://www. planalto. gov.br/ccivil_03/decreto-lei/1937-1946/Del8393.htm. Acesso em: 14 maio 2014.

. LEI No 4.831, DE 5 DE NOVEMBRO DE 1965. Dispõe sobre as novas denominações das Universidades Federais das cidades do Rio de Janeiro e de Niterói. Diário Oficial da União, de 12.1 1. 1965. Disponível em: http://www.procuradoria.ufri.br/legislacao-1/ legislacao-da-ufri/lei-4-83 1-65. Acesso em: 24 maio 2014. 
A educação superior no Brasil: os desafios da expansão e do financiamento e comparações com outros países

Lei n 9.394, de 20 de dezembro de 1996. Estabelece as diretrizes e bases da educação nacional. Diário Oficial [da] República Federativa do Brasil, Brasília, DF, 23 dez. 1996. Disponível em: http://www.planalto.gov.br/ccivil_03/LEIS/19394.htm. Acesso em: 14 maio 2007.

Lei no 10.260, de 12 de julho de 2001. Dispõe sobre o Fundo de Financiamento ao Estudante de Ensino Superior - FIES. Diário Oficial [da] República Federativa do Brasil, Brasilia, DF, 13 jul. 2001. Disponível em: http://www.planalto.gov.br/ccivil_03/Leis/ LEIS_2001/L10260.htm. Acesso em: 20 maio 2011.

Lei $n^{\circ} 11.096$, de 13 de janeiro de 2005. Institui o Programa Universidade para Todos - PROUNI, regula a atuação de entidades beneficentes de assistência social no ensino superior; altera a Lei n 10.891, de 9 de julho de 2004, e dá outras providências.

Diário Oficial [da] República Federativa do Brasil, Brasília, DF, 14 jan. 2005. Disponível em: http://www.planalto.gov.br/ccivil_03/_ato2004/2006/2005/Lei/L 1 1096.htm. Acesso em: 5 jun. 2011.

Lei $\mathbf{n}^{\circ}$ 13.005, de 15 de junho de 2014. Aprova o Plano Nacional de Educação - PNE e dá outras providências. http://www.planalto.gov.br/ccivil_03/_Ato201 1-2014/ Lei/L13005.htm. Acesso em: 9 nov. 2014.

116 BRASIL/IBGE. Projeção da população. 2014. Disponível em: http://www.ibge.gov.br/ home/estatistica/populacao/projecao_da_populacao/2013/default_tab.shtm. Acesso em: 12 dez. 2014.

Contas nacionais trimestrais. 2015. Disponível em: http://www.ibge.gov.br/ home/estatisticas/indicadores/pib.shtm. Acesso em: 31 jan./2015.

Pesquisa nacional por amostra de domicílios (PNAD) - 2012. Disponível em: http://www.ibge.gov.br/home/populacao/default.shtm. Acesso em: 18 jul. 2014.

Ministério da Educação. Construindo o sistema nacional articulado de educação - Plano Nacional de Educação, diretrizes e estratégias de ação - documento final. 2011 . Disponível em: https://conae.mec.gov.br/iamges/stories/pdf/documentos/documento_ final.pdf. Acesso em: 2 fev. 2011.

Ministério da Educação. Instituto Nacional de Estudos e Pesquisas Educacionais Anísio Teixeira. Censo da educação superior: sinopse estatística da educação superior - graduação 1994. Brasília: INEP, 1994. Disponível em: <http://portal.inep.gov.br/superior-censosuperior-sinopse>. Acesso em: 10 jan. 2013. 
Ministério da Educação. Instituto Nacional de Estudos e Pesquisas Educacionais Anísio Teixeira. Censo da educação superior: sinopse estatística da educação superior - graduação 2002. Brasília: INEP, 2002. Disponível em: <http://portal.inep.gov.br/superior-censosuperior-sinopse>. Acesso em: 10 jan. 2013.

Ministério da Educação. Instituto Nacional de Estudos e Pesquisas Educacionais Anísio Teixeira. Censo da educação superior: sinopse estatística da educação superior - graduação 2011 . Brasília: INEP, 2011 . Disponível em: <http://portal.inep.gov.br/superior-censosuperior-sinopse>. Acesso em: 10 jan. 2013.

Censo da educação superior: sinopse estatística da educação superior - graduação 2012. Brasília: INEP, 2012. Disponível em: http://portal.inep.gov.br/superior-censosuperior-sinopse. Acesso em: 10 jan. 2014.

. Acesso a microdados gerados pelo Inep. 2012. BRASÍLIA: INEP, 2012a. Disponível em: http://portal.inep.gov.br/basica-levantamentos-microdados. Acesso em: 20 jan. 2015.

Investimentos públicos em educação. Percentual do Investimento Direto em relação ao PIB por nível de ensino. 2011 . Disponível em: http://portal.inep.gov.br/web/guest/ estatisticas-gastoseducacao-indicadores_financeiros-p.t.d._nivel_ensino.htm. Acesso em: 5 dez. 2011.

Ministério da Fazenda. Relatório Resumido da Execução Orçamentária do

Governo Federal - dezembro de 2010. Disponível em: https://www.tesouro.fazenda.gov. br/downloads/lei_responsabilidade/RRdez2009.pdf. Acesso em: 10 jan. 2010.

Constituição da República Federativa do Brasil de 1988. Disponível em: http:// www.planalto.gov.br/ccivil_03/constituicao/constitui\%C3\%A7ao.htm. Acesso em: 1 mar. 2014.

BRESSER PEREIRA, Luiz Carlos; SPINK, Peter (Org.) Reforma do Estado e administração pública. Rio de Janeiro: Editora da Fundação Getúlio Vargas, 1998.

CASTRO, Jorge Abrahão. Financiamento e gasto público da educação básica no Brasil e comparação com alguns países da OCDE e América Latina. Educação \& Sociedade, Campinas, v. 26, n. 92, p. 841-858, out. 2005.

CUNHA, Luiz Antonio. A educação nas constituições brasileiras: análise e propostas. Educação \& Sociedade, Campinas, n. 22, p. 15-24, set./dez. 1985.

A universidade temporã: o ensino da colônia à era Vargas. Rio de Janeiro: Francisco Alves, 1986. 
A educação superior no Brasil: os desafios da expansão e do financiamento e comparações com outros países

Qual universidade? São Paulo: Cortez; Campinas: Autores Associados, 1989.

○úblico e o privado na educação superior brasileira: fronteira em movimento? In: TRINDADE, Hélgio (Org.). Universidade em ruínas na república dos professores. Petrópolis: Vozes, 1999.

DOURADO, Luiz Fernandes; OLIVEIRA, João Ferreira. Políticas educacionais e reconfiguração da educação superior no Brasil. In: DOURADO, Luiz Fernandes, CATANI, Afrânio Mendes (Org.). Universidade pública, políticas e identidade institucional. Campinas: Autores Associados; Goiânia: Editora da UFG, 1999.

DOURADO, Luiz Fernandes. $\bigcirc$ público e o privado na agenda educacional brasileira. In: FERREIRA, Naura Syria Carapeto; AGUIAR, Márcia Ângela da Silva (Org.). Gestão da educação: impasses, perspectivas e compromissos. São Paulo: Cortez, 2000.

A interiorização do ensino superior e a privatização do público. Goiânia: Editora da UFG, 2001.

EUA. CIA. The world factbook. Disponivel em: https://www.cia.gov/library/publications/ the-worldfactbook/region/region_soa.html. Acesso em: 23 jan.2015.

FÁVERO, Maria de Lourdes de Albuquerque (Org.). A universidade em questão. São Paulo: Cortez/Autores Associados, 1989.

Da universidade modernizada à universidade disciplinada: Atcon e Meira Mattos. São Paulo: Cortez; Campinas: Autores Associados, 1991.

NOTA pública. Associação Nacional de Pesquisa em Financiamento da Educação - FINEDUCA. O PNE e o financiamento da educação. Disponível em: http://www.redefinanciamento.ufpr.br/nota_pne.pdf. Acesso em: 5 jun. 2014.

FONSECA, Dirce Mendes. O pensamento privatista em educação. Campinas: Papirus, 1992.

GOMES, Alfredo Macedo. Política de avaliação da educação superior: controle e massificação. Educação \& Sociedade, Campinas, v. 23, n. 80, p. 275-298, set. 2002.

MARTINS, Carlos Benedito. Ensino pago: um retrato sem retoques. São Paulo: Cortez, 1988.

público e o privado na educação superior brasileira nos anos 80. Cadernos CEDES, Campinas, v. 25, p. 63-74, 1991.

O ensino superior privado no Distrito Federal. Cadernos de Pesquisa, São Paulo, n. 102, p. 157-187, nov. 1997. 
NEGRI, Barjas. O financiamento da educação no Brasil. Brasília: Inep, 1997. (Série Documental e textos para discussão, n. 1).

PINTO, José Marcelino Rezende. Relatório do Grupo de Trabalho sobre Financiamento da Educação. Revista Brasileira de Estudos Pedagógicos, Brasília, v. 82, n. 200/201/202, p. 1 17-136, jan./dez. 2001.

Quanto custa financiar um PNE "prá valer"? 2011. Disponível em: http://www2. camara.gov.br/atividade-legislativa/comissoes-temporarias/especiais/54a-legislatura/ pl-8035-10-plano-nacional-de-educacao. Acesso em: 20 jun. 2011.

SGUISSARDI, Valdemar. Universidade, fundação e autoritarismo: o caso da UFSCar. São Paulo: Estação Liberdade; São Carlos: EdUFScar, 1993.

. (Org.). Educação superior: velhos e novos desafios. São Paulo: Xamã, 2000.

2009.

Universidade brasileira no século XXI: desafios do presente. São Paulo: Cortez,

SGUISSARDI, Valdemar; SILVA JÚNIOR, João dos Reis. Novas faces da educação superior no Brasil: reforma no Estado e mudança na produção. Bragança Paulista: EDUSF, 1999.

SIQUEIRA, Tânia Cristina Alves. O trabalho docente nas instituições de ensino superior privado em Brasília. 2006. 204 f. Tese (Doutorado em Sociologia) - Programa de PósGraduação em Sociologia, Universidade de Brasília, Brasília, 2006.

TRINDADE, Hélgio (Org.). Universidade em ruínas na república dos professores. Petrópolis: Vozes, 1999.

Profa. Dra. Vera Lúcia Jacob Chaves Universidade Federal do Pará Instituto de Ciências de Educação

Programa de Pós-Graduação em Educação Coordena o Grupo de Estudos e Pesquisas sobre Educação Superior | GEPES Pesquisadora da Rede Universitas/Br Pesquisadora do Observatório da Educação "Políticas da Expansão da Educação Superior" E-mail | veraluciajacob@gmail.com 
Artigo

A educação superior no Brasil: os desafios da expansão e do financiamento e comparações com outros países

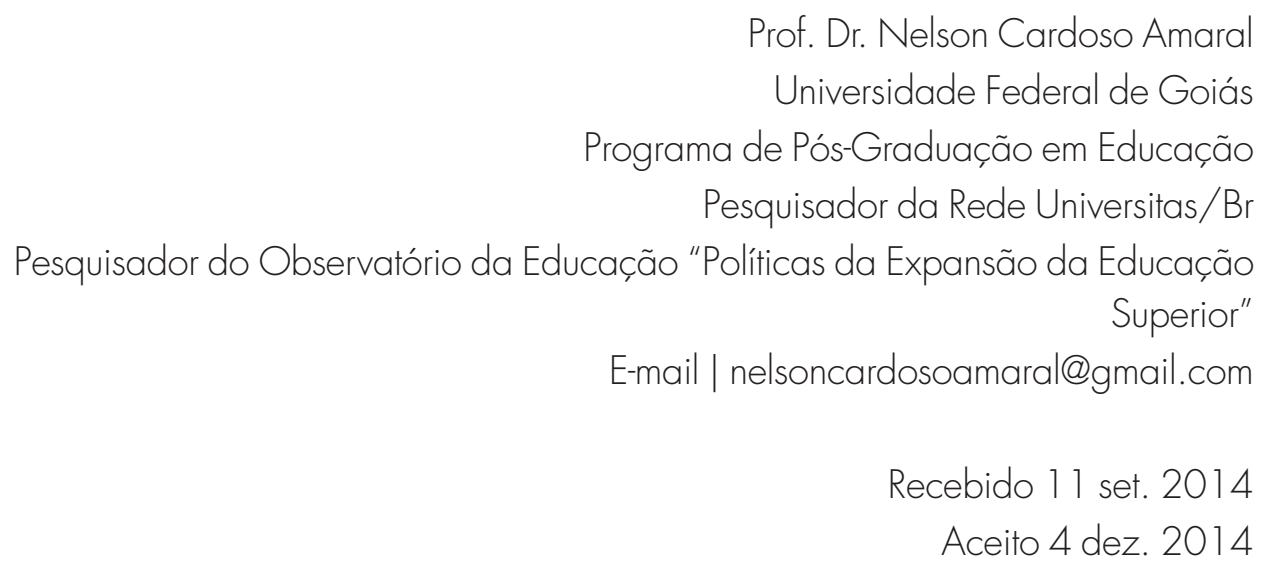

